\title{
Myths, beliefs, and conspiracies about COVID-19 Vaccines in Sindh, Pakistan: An online cross-sectional survey
}

\author{
Qamar Abbas ${ }^{1}$, Fatima Mangrio², and Sunil Kumar ${ }^{2}$ \\ ${ }^{1}$ University of Bahrain \\ ${ }^{2}$ University of Sindh
}

March 8, 2021

\begin{abstract}
Abstract Background Pakistan has already encountered intense opposition to polio vaccination due to myths and misinformation, now the unfavorable opinions of COVID-19 vaccinations among the population would have catastrophic consequences for attempts to end the pandemic. Methods A web-based cross-sectional study was conducted in the general population of Sindh, Pakistan in January 2021. 31 items based on vaccines availability, safety, and myths, the questionnaire was designed and randomly distributed through a google form link. Results were analyzed using descriptive and Chi-square tests. Results A total of 774 responses were recorded from 23 districts of Sindh, Pakistan. The majority of participants $(\mathrm{n}=00,00.0 \%)$ were not aware of the presence of the COVID-19 vaccine in Pakistan. Results found the significant relationship of conspiracies and myths with an education level of participants, to make Muslims infertile, illiterate showed (Yes $\mathrm{n}=45, \mathrm{No}=27$ ) while postgraduate (Yes $\mathrm{n}=11, \mathrm{No}=88)(\chi 2=109.6, \mathrm{P}>0.000)$. Participants showed doubt about the safety of vaccines, (Yes $\mathrm{n}=464,59.9 \%, \mathrm{No}=310$, $40.1 \%$ ). Other responses related to side effects of the vaccine were also highly significant, participants showed that vaccine side effects (Yes $\mathrm{n}=462,59.7 \%, \mathrm{No}=312,40.3 \%)$, Pregnant or breastfeeding women should not get vaccinated (Yes $\mathrm{n}=468,59.8 \%$, $\mathrm{No}=311,40.1 \%$ ) and people with underlying conditions should not get vaccinated (True $\mathrm{n}=389,50.3 \%$, False $=385,49.7 \%$ ) Conclusion The proportion of varying public doubts in vaccines' safety and efficacy and the presence of myths, conspiracies will be a major barrier to vaccine uptake.
\end{abstract}

Myths, beliefs, and conspiracies about COVID-19 Vaccines in Sindh, Pakistan: An online cross-sectional survey

Running title: COVID-19 Vaccines awareness

Qamar Abbas ${ }^{1}$, Fatima Mangrio ${ }^{2}$, Sunil Kumar ${ }^{2}$

${ }^{1}$ Department of Biology, College of Science, University of Bahrain, Sakhir, 32038 Kingdom of Bahrain

${ }^{21}$ Department of Physiology and Medical Laboratory Technology, University of Sindh, Jamshoro, 76080Sindh, Pakistan

\section{Keywords}

COVID-19, vaccines, Myths, Sindh Pakistan, Vaccines awareness, Pandemic

\section{Corresponding Author}

Qamar Abbas, PhD

Department of Biology, College of Science, University of Bahrain, Sakhir, 32038 Kingdom of Bahrain qamar.abbas.qau@gmai.com 


\section{Disclosures}

Authors declare no any conflict of interest

Myths, beliefs, and conspiracies about COVID-19 Vaccines in Sindh, Pakistan: An online cross-sectional survey

Qamar Abbas ${ }^{1}$, Fatima Mangrio ${ }^{2}$, Sunil Kumar ${ }^{2}$

${ }^{1}$ Department of Biology, College of Science, University of Bahrain, Sakhir, 32038 Kingdom of Bahrain

${ }^{2}$ Department of Physiology and Medical Laboratory Technology, University of Sindh, Jamshoro, Sindh, Pakistan

\section{Abstract \\ Background}

Pakistan has already encountered intense opposition to polio vaccination due to myths and misinformation, now the unfavorable opinions of COVID-19 vaccinations among the population would have catastrophic consequences for attempts to end the pandemic.

\section{Methods}

A web-based cross-sectional study was conducted in the general population of Sindh, Pakistan in January 2021. 31 items based on vaccines availability, safety, and myths, the questionnaire was designed and randomly distributed through a google form link. Results were analyzed using descriptive and Chi-square tests.

Results

A total of 774 responses were recorded from 23 districts of Sindh, Pakistan. The majority of participants $(\mathrm{n}=00,00.0 \%)$ were not aware of the presence of the COVID-19 vaccine in Pakistan. Results found the significant relationship of conspiracies and myths with an education level of participants, to make Muslims infertile, illiterate showed (Yes $\mathrm{n}=45, \mathrm{No}=27)$ while postgraduate (Yes $\mathrm{n}=11, \mathrm{No}=88)\left(\chi_{2}=109.6, \mathrm{P}>\right.$ 0.000). Participants showed doubt about the safety of vaccines, (Yes $\mathrm{n}=464,59.9 \%, \mathrm{No}=310,40.1 \%$ ). Other responses related to side effects of the vaccine were also highly significant, participants showed that vaccine side effects (Yes $\mathrm{n}=462,59.7 \%, \mathrm{No}=312,40.3 \%$ ), Pregnant or breastfeeding women should not get vaccinated (Yes $\mathrm{n}=468,59.8 \%, \mathrm{No}=311,40.1 \%$ ) and people with underlying conditions should not get vaccinated (True $\mathrm{n}=389,50.3 \%$, False $=385,49.7 \%$ ).

\section{Conclusion}

The proportion of varying public doubts in vaccines' safety and efficacy and the presence of myths, conspiracies will be a major barrier to vaccine uptake.

\section{Keywords}

COVID-19, vaccines, myths, Sindh Pakistan, Vaccines awareness, Pandemic

\section{What's known?}

Perception, attitudes and awareness about COVID-19

Prevalence of COVID-19

\section{What's new?}

Safety and efficacy of COVID-19 vaccines

Myths and conspiracies regarding COVID-19 vaccines

Education level and COVID-19 vaccines information of peoples 


\section{Introduction}

COVID-19 has been quickly circulating across the world since December 2019. Not surprisingly, discussion about COVID-19 is also on the rise [1]. Because of the exponential growth in Covid-19 cases, widespread myths and misinformation regarding the disease's transmission triggered an "infodemic," according to the Global Health Organization [2]. Myth is commonly thought of as a folktale category that involves tales that play an important role in people's everyday lives [3]. These are often endorsed by religious and government figures, and they express the general workings of a collective public and form people's trust. Social and religious views play an important role in affecting popular opinion in a given country and influencing the formation or adoption of myths [4].

Vital oils, colloidal silver, and other myths about how to cure manage, and defend against COVID-19 continue to circulate across face-to-face and often web-based media [5]. While some believe that a hot climate destroys viruses, COVID-19 is spreading to some hot countries as well. Few people consider taking zinc, ginger, nectar, a lot of Indian spices, and other vitamins to prevent COVID-19 [6].

According to research, those with a lower level of education or who are illiterate, the unemployed, younger generations, and certain ethnic groups are more hesitant.

Vaccine apprehension continues to be a significant challenge for Pakistan, despite various conspiracy theories. Such theories are largely to blame for the country's failure to eradicate polio. Among others, reports of low vaccine consistency, concerns regarding dosing guidelines, religious bans ("infidel vaccine"), and speculation about the existence of the active virus in vaccinations are some of the more popular arguments obstructing the country's anti-polio drive [7].

Unfortunately, in Pakistan, a conspiracy hypothesis about the COVID-19 vaccine is reportedly circulating. Recently, a well-known Pakistani political commentator and columnist reported that the virus was a grand illusion intended to attack Islamic countries and allow Jews to dominate the world, with nano-chips implanted in people's bodies to gain power over 5G towers [8]. An ex-foreign minister of Pakistan proposed a parallel theory, accusing the US of inventing the virus in the United Kingdom and then moving it to China for global dissemination [9].

These theories are widely debated on social media in the Pakistani culture. Such conspiracy narratives could sow seeds of resistance against upcoming COVID-19 vaccination programs in the world, where vaccine apprehension is a major barrier to preventing vaccine-preventable diseases. Since a long-term lockdown is not feasible in many countries due to economic instability, vaccination supply could be the best solution to prevent the pandemic from spreading.

It was recently discovered that public knowledge of infectious diseases is strongly linked to vaccine confidence [10]. A global survey of 140,000 people on "attitudes to vaccines" found that countries with successful public-awareness programs against multiple infectious diseases have very high rates of consensus on vaccine prevention, efficacy, and value [11]. In a pandemic, recognizing myths and beliefs is important because they can impact preventative and containment efforts. As a result, in this study, myths and misconceptions regarding COVID-19 vaccines were analyzed in the general population of Sindh. To our best of knowledge, there hasn't been any research done in Sindh on myths and misconceptions about Covid-19 vaccines.

\section{Methods}

A web-based cross-sectional survey study was designed through "Google Form" to record responses from the Sindh province of Pakistan in January 2021.

Study area

Sindh is one of the four provinces of Pakistan located in its south. Sindh is the home of almost 47.9 million humans. Sindh province is comprised of seven divisions 29 districts further these districts are subdivided into Tehsils and union councils [12]. 


\subsection{Development of research tool}

A questionnaire with 31 items was designed in English and in the local language (Sindhi) using already published material on COVID-19, after listening to local community concerns and discussion regarding COVID-19 vaccines and myths related to other vaccines in Sindh, Pakistan.

Content of the survey questionnaire

The questionnaire contains 31 items that take 4-6 min to complete. The questionnaire was divided into four sections; the first section contains 10 questions about demographic information of the participants, 2 questions about COVID-19 vaccines availability in Pakistan, 13 questions related to vaccines safety and potency, and six questions about myths and conspiracies about COVID-19 vaccines \& last question about the consent of respondent for participation in the study.

\subsection{Ethical consideration}

The questionnaire was reviewed and approved by the ethical committee of the Department of Physiology University of Sindh, Jamshoro, Sindh, Pakistan. The participants were requested for consent and willingness in study and confidentiality of all the participants was maintained.

\subsection{Distribution of questionnaire}

The final survey link was disseminated among the peoples of Sindh province in the form of "Google Form" by means of different media platforms, for example, E-mail, WhatsApp, and Facebook. Accordingly, the link was sent to individuals apart from the first main point of contact and was requested to forward to others. Responses from illiterate peoples were obtained physically after explaining the questionnaire in the local language and then these responses were transformed into the online form.

\subsection{Statistical analysis}

Data were analyzed using IBM SPSS statistics version 23. To determine the associated factors with misinformation and myths, chi-square was calculated with the significant level was determined as p-value, $\mathrm{p}<0.05$ was considered as statistically significant.

\section{Results}

An online survey, about COVID-19 vaccine misinformation, mistrust, and myths were conducted in the Sindh province of Pakistan. A total of 774 responses were recorded. All the participants give their consent in publishing the data without mentioning their identity. All the respondents were from Sindh province and above 16 years of age. The responses of illiterate and those who don't have access to the internet their responses were recorded physically and then shifted to online.

\section{Part-I: Demographics}

Geographic patterns of study sample across various districts of Sindh province was created using ArcGIS 10.8, the responses were recorded from 23 major district of Sindh Pakistan. $66.3 \%$ of participants were from rural areas and $34.7 \%$ of the participants from urban areas. Highest number of responses were recorded from Larkana (20.93\%) followed by Mirpurkhas (13.30\%) and Hyderabad (12.27\%, Fig.1). The majority of the respondent were male $(n=561,72.5 \%)$ female $(n=210,27.1 \%)$ and $(n=03,0.041 \%)$ transgender were recorded. Age of participants were divided into five groups, highest number of responses were from youngest peoples age group 21-30 year $(\mathrm{n}=435,56.2 \%) 16-20(\mathrm{n}=167,21.6 \%), 31-40(\mathrm{n}=114,14.7 \%), 41-60(\mathrm{n}=48$, $6.2 \%)$ and lowest responses from older peoples above $60(\mathrm{n}=10,1.3 \%)$. In marital status 3 peoples did not showed their marital status while singles were $(n=545,70.4 \%)$, married $(n=224,28.9 \%)$ and $3(0.4 \%)$ were divorced. Education was the main indicator of the present study respondent education qualification was divided into five categories among all categories highest responses from graduates $(\mathrm{n}=414,53.5 \%)$ followed by secondary $(\mathrm{n}=124,16 \%)$, postgraduate $(\mathrm{n}=99,12.8 \%)$, Illiterate $(\mathrm{n}=72,9.3 \%)$ and Primary $(\mathrm{n}=65$, $8.4 \%)$. Most of the participants were students $(n=434,56.1 \%)$, labourer were $(n=94,12.1 \%)$ and govt employee were $(n=87,11.2 \%)$. In religious column most of the responses were from Muslim's $(n=589$, 
$76.1 \%)$, Hinduisim $(\mathrm{n}=181,23.4 \%)$ and Christian were $(\mathrm{n}=3,0.4 \%)$. Most of the respondents were from lower income position $(\mathrm{n}=490,63.3 \%)$ earns only less than 20,000PKR per month (Table.1)

Part-II: Vaccine availability

A significant number of participants were aware of the COVID-19 vaccine (Yes, $n=506,65.4 \%$ and No, $\mathrm{n}=268,34.6 \%$ ). Interestingly when the response of vaccine availability in Pakistan was analyzed, results showed that significantly (No, $n=503,65 \%$ and Yes, $n=271,35 \%$ ) majority of participants were not aware of the presence of COVID-19 vaccine in Pakistan, these responses were further analyzed among gender, education and with the living area, there was not any significant difference obtained (Table. 2).

Part-III: Vaccine conspiracies and myths

There were six questions about the vaccine myths and conspiracies included. In general, the majority of the responses showed COVID-19 vaccine is not a conspiracy, to make infertile Muslims/ any Haram ingredients (forbidden in Islam) or anti-Islamic agenda (Fig. 2.), these responses were further statistically analyzed using $\chi^{2}$ with the education level of participants. Surprisingly, the results found the significant relationship of conspiracies and myths with the education level of participants, to make Muslims infertile illiterate showed (Yes $n=45, \mathrm{No}=27)$ while postgraduate (Yes $\mathrm{n}=11, \mathrm{No}=88)\left(\chi^{2}=109.6, \mathrm{P}>0.000\right)$. In other question COVID-19 vaccine is prepared only for making money similar type difference was obtained illiterate showed (Yes $\mathrm{n}=67, \mathrm{No}=5)$ while postgraduate (Yes $\mathrm{n}=34, \mathrm{No}=65)\left(\chi^{2}=140.8, \mathrm{P}>0.000\right)$. Similarly, for other myths and conspiracies like a vaccine contains Haram ingredients (forbidden in Islam) or anti-Islamic agenda highly significant difference was showed between illiterate and educated respondents $(\mathrm{P}>0.000$, Table...)

\section{Part-IV: Vaccine safety and potency}

In this section, the 12 questions related to vaccine safety and potency were included. In the first question, as shown in Fig. 3 participants showed doubt about the safety of the vaccine, because participants think that vaccine prepared quickly which's why the vaccine is not safe for use (Yes $\mathrm{n}=464,59.9 \%, \mathrm{No}=310$, $40.1 \%$ ). Other responses related with side effects of vaccine were also in negative, participants showed that vaccine side effects (Yes $\mathrm{n}=462,59.7 \%, \mathrm{No}=312,40.3 \%$ ), Pregnant or breastfeeding women should not get vaccinated (Yes $\mathrm{n}=468,59.8 \%, \mathrm{No}=311,40.1 \%$ ) and people with underlying conditions should not get vaccinated (True $\mathrm{n}=389,50.3 \%$, False $=385,49.7 \%$ ). On the other hand, participants showed significant trust in the potency of the vaccine, despite the less than 100\% efficacy of the COVID-19 vaccine, would you still prefer to be vaccinated (Yes $\mathrm{n}=407,52.6 \%, \mathrm{No}=367,47.4 \%$ ) similar trust in potency of the vaccine was recorded in all related questions as shown in table $2 \&$ fig. $2 \& 3$. Moreover, we found strong significant $(\mathrm{P}>0.000)$ relationships between vaccine myths, misinformation, and conspiracies with the education levels.

\section{Discussion}

In the present study, we aimed to investigate how people of Sindh view a COVID-19 vaccine, particularly in terms of quick formulation of vaccine, availability, side effects, myths, and misinformation in the local community. To the best of our literature search, this is the first study in investigating the myths misinformation of the COVID-19 vaccine in the local community of Sindh, Pakistan. Nowadays, vaccine acceptance has been a big challenge, which upraised the concern of trust in the immunization process of COVID-19 for the public even in developed countries, a similar type of myths and conspiracies were also faced for measles, polio, rubella, and mumps due to myths and misinformation results in decreased vaccination [13, 14]. Pakistan has faced these issues for decades for Polio vaccines and now the same issue raised for COVID-19. Trust in vaccination impair can coexist in various forms of vaccination hesitancy [15], as it can be associated with myths, misinformation, and conspiracies in vaccination efficacy and practicality, or comprehensive rejection of vaccination [16]. These are the constant issues in public trust regarding the adverse effects of vaccines.

Beliefs in vaccines associated with education level have been studied in Canada, the US, and other countries. Importantly, concerns regarding vaccine safety were also found in well-educated areas [17]. Our findings are also accordingly, educated participants were also in doubts about the safety of vaccines, and moreover, 
our results indicated that educated participants were in favor of immunity through vaccines, and with the increasing education level the results showed that participants were against the myths.

The most widely repeatedly cited trust comprised that vaccines can cause disease; infants immune system can be saturated if injected too many vaccines frequently, vaccines contains dangerous elements in the formulation, Children with underlying health conditions are more vulnerable to vaccines side effects; the purpose of vaccines is making money; naturally immunity is more powerful than with vaccines [18], our findings were also similar, results suggested that majority of participants were in belief that peoples with underlying conditions and pregnant or breastfeeding should not get vaccinated as it can be harmful.

Globally, another predictor is religion's most widely studied indicator in vaccine hesitancy researches. Studies indicated that higher religiosity was connected with an increasing ratio of vaccine rejection [19]. Our results did not show any religious involvement in vaccines myths conspiracies or misinformation which lead to vaccines refusal. Associated with the already published findings from Canada and other countries [20], importantly we also found that education level is the key indicator of vaccine rejections illiterate and less educated showed higher rejection and more trust in myths and conspiracies.

\section{Conclusion}

The results from the present study suggest that the myths, mistrust, and conspiracies about the COVID-19 vaccine's safety and efficacy are present in less educated most significantly in illiterate peoples. Therefore, it's very important for policymakers and the government to educate the people to minimize vaccine hesitancy. Public health experts and policymakers should start awareness campaigns on TV, radio, and other media platform and also through distributing the vaccine information leaflets or broachers to the general public for cracking myths and misinformation that leads to vaccine hesitancy.

\section{Disclosures}

Authors declare no any conflict of interest

\section{Reference}

1. Singh L, Bansal S, Bode L, Budak C, Chi G, Kawintiranon K, Padden C, Vanarsdall R, Vraga E, Wang Y. A first look at COVID-19 information and misinformation sharing on Twitter. arXiv preprint arXiv:2003.13907. 2020 Mar 31.

2. World Health Organization. Coronavirus disease 2020 (COVID-19): situation report, 82.

3. Grover S, Sahoo S, Mehra A, Avasthi A, Tripathi A, Subramanyan A, Pattojoshi A, Rao GP, Saha G, Mishra KK, Chakraborty K. Psychological impact of COVID-19 lockdown: An online survey from India. Indian Journal of Psychiatry. 2020 Jul;62(4):354.

4. Sola Morales S. Myth and the construction of meaning in mediated culture. KOME: An International Journal of Pure Communication Inquiry. 2013;1(2):33-43.

5. Swetha G, Geetha RV. MYTHS VS FACTS-COVID-19-QUESTIONNAIRE SURVEY. PalArch's Journal of Archaeology of Egypt/Egyptology. 2020 Nov 28;17(7):1068-81.

6. Gilbert MT, Jenkins DL, Götherstrom A, Naveran N, Sanchez JJ, Hofreiter M, Thomsen PF, Binladen J, Higham TF, Yohe RM, Parr R. DNA from pre-Clovis human coprolites in Oregon, North America. Science. 2008 May 9;320(5877):786-9.

7. Ali MC, Chen J, Zhang H, Li Z, Zhao L, Qiu H. Effective extraction of flavonoids from Lycium barbarum L. fruits by deep eutectic solvents-based ultrasound-assisted extraction. Talanta. 2019 Oct $1 ; 203: 16-22$.

8. Staff O. Bill Gates' coronavirus vaccine will have nano trackers, will be controlled via 5G satellites to take Islam out of Muslims: Pakistani 'expert'Zaid Hamid. OpIndia. OpIndia. Available at: https://www. opindia. com/2020/05/pakistan-zaid-hamid-coronavirus-vaccine-bill-gates-nanotrackers-5g-satellite-muslims/. Accessed June. 2020;9:2020.

9. Staff O. Coronavirus is not natural but invented in a laboratory by Israel, US and UK: Former Pakistan Foreign Minister comes up with a bizarre conspiracy theory. OpIndia. OpIndia. Available 
at: https://www. opindia. com/2020/03/coronavirus-pakistan-minister-conspiracy-theory-created-inus-uk-clean-chit-china/. Accessed June. 2020;9:2020.

10. El-Showk S. Neanderthal clues to brain evolution in humans. Nature. 2019 Jul 1;571(7766):S10-.

11. Rozbroj T, Lyons A, Lucke J. Vaccine-hesitant and vaccine-refusing parents' reflections on the way parenthood changed their attitudes to vaccination. Journal of community health. 2020 Feb;45(1):63-72.

12. Chandir S, Siddiqi DA, Mehmood M, Setayesh H, Siddique M, Mirza A, Soundardjee R, Dharma VK, Shah MT, Abdullah S, Akhter MA. Impact of COVID-19 pandemic response on uptake of routine immunizations in Sindh, Pakistan: an analysis of provincial electronic immunization registry data. Vaccine. 2020 Oct 21;38(45):7146-55.

13. Vulpe SN, Rughiniş C. Social amplification of risk and "probable vaccine damage": A typology of vaccination beliefs in 28 European countries. Vaccine. 2021 Feb 8.

14. Ahmed SS, Schur PH, MacDonald NE, Steinman L. Narcolepsy, 2009 A (H1N1) pandemic influenza, and pandemic influenza vaccinations: what is known and unknown about the neurological disorder, the role for autoimmunity, and vaccine adjuvants. Journal of autoimmunity. 2014 May 1;50:1-1.

15. Hussain SF, Boyle P, Patel P, Sullivan R. Eradicating polio in Pakistan: an analysis of the challenges and solutions to this security and health issue. Globalization and health. 2016 Dec;12(1):1-9.

16. Crescitelli MD, Ghirotto L, Sisson H, Sarli L, Artioli G, Bassi MC, Appicciutoli G, Hayter M. A metasynthesis study of the key elements involved in childhood vaccine hesitancy. Public Health. 2020 Mar $1 ; 180: 38-45$.

17. Wei F, Mullooly JP, Goodman M, McCarty MC, Hanson AM, Crane B, Nordin JD. Identification and characteristics of vaccine refusers. BMC pediatrics. 2009 Dec;9(1):1-9.

18. Dubé E, Vivion M, MacDonald NE. Vaccine hesitancy, vaccine refusal and the anti-vaccine movement: influence, impact and implications. Expert review of vaccines. 2015 Jan 2;14(1):99-117.

19. Reuben R, Aitken D, Freedman JL, Einstein G. Mistrust of the medical profession and higher disgust sensitivity predict parental vaccine hesitancy. PloS one. 2020 Sep 2;15(9):e0237755.

20. Wei F, Mullooly JP, Goodman M, McCarty MC, Hanson AM, Crane B, Nordin JD. Identification and characteristics of vaccine refusers. BMC pediatrics. 2009 Dec;9(1):1-9.

\section{Hosted file}

Fig.1.pdf available at https://authorea.com/users/400163/articles/512518-myths-beliefs-andconspiracies-about-covid-19-vaccines-in-sindh-pakistan-an-online-cross-sectional-survey

\section{Hosted file}

Fig.2.pdf available at https://authorea.com/users/400163/articles/512518-myths-beliefs-andconspiracies-about-covid-19-vaccines-in-sindh-pakistan-an-online-cross-sectional-survey

\section{Hosted file}

Fig.3.pdf available at https://authorea.com/users/400163/articles/512518-myths-beliefs-andconspiracies-about-covid-19-vaccines-in-sindh-pakistan-an-online-cross-sectional-survey

\section{Hosted file}

Table 1.pdf available at https://authorea.com/users/400163/articles/512518-myths-beliefsand-conspiracies-about-covid-19-vaccines-in-sindh-pakistan-an-online-cross-sectionalsurvey

\section{Hosted file}

Table 2.pdf available at https://authorea.com/users/400163/articles/512518-myths-beliefsand-conspiracies-about-covid-19-vaccines-in-sindh-pakistan-an-online-cross-sectionalsurvey 